\title{
Effect of Lidocaine on the Electrophysiological
}

\section{Properties of Ventricular Muscle and Purkinje Fibers}

\author{
J. Thomas Bigger, Jr., and William J. Mandel \\ From the Departments of Pharmacology and Medicine, College of Physicians \\ and Surgeons, Columbia University, New York 10032
}

A B S T R A C T Preparations of right ventricular papillary muscle and false tendon (Purkinje fiber) were obtained from dog hearts, placed in a bath perfused with Tyrode solution, and observed both under control conditions and during exposure to lidocaine in concentrations from $1 \times 10^{-7}$ to $5 \times 10^{-4} \mathrm{~mole} / \mathrm{liter}$. Transmembrane voltages were recorded from both ventricular muscle (VM) and Purkinje fibers (PF) of spontaneously beating and electrically driven preparations. Low concentrations $\left(1 \times 10^{-8}\right.$ and $\left.1 \times 10^{-5} \mathrm{~mole} / \mathrm{liter}\right)$ attenuated or abolished phase 4 (diastolic) depolarization and spontaneous firing in $\mathrm{PF}$ without decreasing their diastolic excitability. Concentrations of $1 \times 10^{-6} \mathrm{~mole} /$ liter produced maximal shortening of both action potential duration (APD) and effective refractory period (ERP) and made the ERP long relative to APD; the latter alteration was more prominent in VM. At concentrations $\leq 1 \times 10^{-5} \mathrm{~mole} / \mathrm{liter}$, lidocaine either caused a slight increase or no change in peak maximum rate of phase 0 depolarization $\left(V_{\max }\right.$ ) and membrane responsiveness, the relationship between transmembrane activation voltage (MAV) and $\vec{V}_{\max }$ of the resultant action potential; these concentrations had no significant effect on resting potential (RP) in VM, maximal diastolic transmembrane voltage $\left(\mathrm{DTMV}_{\max }\right)$ in $\mathrm{PF}$, or action potential amplitude in either fiber type.

High (toxic) concentrations ( $\geq 1 \times 10^{-4}$ mole/liter) did not cause further shortening of APD or ERP in either VM or PF but did produce a decrease in peak $V_{\max }$ of phase 0 and membrane responsiveness. In most cases, these concentrations also caused a decrease in $\mathrm{RP}$ or $\mathrm{DTMV} \max$ and action potential amplitude, with

This study was presented in part at meetings of the American College of Cardiology, New York, 1969 and the American Pharmacological Society, Atlantic City, N. J., 1969.

Dr. Bigger is a Senior Investigator of the New York

Heart Association; Dr. Mandel is the Martha Lyon Slater Fellow of the New York Heart Association.

Received for publication 5 June 1969 and in revised form 5 August 1969. progression to bizarre action potential depolarization and inexcitability. These properties of lidocaine are strikingly different from those of quinidine or procaine amide. The mechanisms responsible for lidocaine's in vivo antiarrhythmic action are discussed.

\section{INTRODUCTION}

Lidocaine hydrochloride has been used sporadically as a cardiac antiarrhythmic drug since 1950 (1) and in the past few years, has been frequently used to treat ventricular arrhythmias which occur during and after cardiac surgery (2-5) and myocardial infarction (6-9). The antiarrhythmic and electrophysiological properties of lidocaine were assumed to be similar to those of procaine amide. This assumption is not unreasonable when one considers the similarity of structure and of local anesthetic properties shared by these two drugs. Indeed, the strongest arguments made for the clinical use of lidocaine in the treatment of arrhythmias rather than procaine amide or quinidine usually have been related to either the pronounced differences in its mode and rate of metabolism (4-8) or to differences between the effects of lidocaine and these two drugs on blood pressure, cardiac output, and myocardial contractility (9-12). Differences in electrophysiological properties or antiarrhythmic spectrum usually have been neglected in such discussions.

However, recent reports suggest significant differences between antiarrhythmic and electrophysiological properties of lidocaine and procaine amide or quinidine (13). For instance, lidocaine, at therapeutic levels, seems to have less effect on excitability and intraventricular conduction than procaine amide or quinidine (14). Lidocaine is more effective against arrhythmias induced by digitalis $(7,15-17)$ and less effective against atrial arrhythmias such as atrial fibrillation or flutter than procaine amide or quinidine (6-9). These observations are sufficient to question the hypothesis that the electro- 
physiological properties of lidocaine are identical with or very similar to those of procaine amide or quinidine.

As pointed out previously (18-20), ventricular arrhythmias are best understood in terms of alterations in automaticity, conductivity, and the associated changes in the electrophysiological properties of the Purkinje fiber. Automatic ventricular rhythms almost certainly originate in the Purkinje fibers (PF) and the impulse in reentrant ventricular arrhythmias frequently must utilize these fibers as a portion of the reentrant circuit. With these considerations in mind, a study was undertaken to evaluate the effects of lidocaine hydrochloride on the transmembrane potentials of isolated perfused canine Purkinje and ventricular muscle (VM) fibers. The results obtained are compared with those previously reported from studies of the action of procaine amide or quinidine in the same cell types of this same species (21) and used as the basis for speculation about the mechanism of action of lidocaine as a clinical antiarrhythmic agent.

\section{METHODS}

Mongrel dogs weighing 10-15 kg were anesthetized with sodium pentobarbital $(30 \mathrm{mg} / \mathrm{kg}$, intravenously). The heart was rapidly removed and dissected in cool oxygenated Tyrode solution. False tendon (Purkinje fiber) preparations were dissected from either ventricle, leaving the adjacent

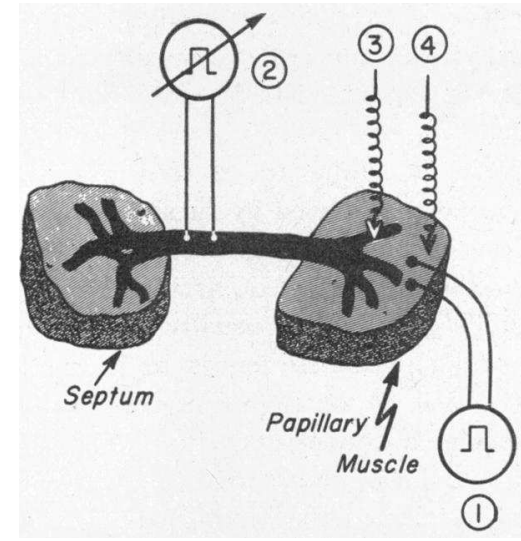

FIGURE 1 A diagram of the typical experimental arrangement. The free-running false tendon (Purkinje fibers) is shown as the black strand between a portion of interventricular septum (left) and a portion of papillary muscle (right). A pair of silver extracellular electrodes (1) was placed on the surface of the papillary muscle and used for stimulation. Another pair of silver extracellular electrodes (2) was placed on the surface of the false tendon, 10-15 $\mathrm{mm}$ distance from the papillary muscle. This pair of electrodes was either used for recording during the measurement of the effective refractory period in Purkinje fibers or for direct stimulation of the fibers. Glass microelectrodes, filled with $3 \mathrm{M} \mathrm{KCl}$, were used to record transmembrane voltages from ventricular muscle (4) and from a nearby Purkinje fiber (3). The distance between microelectrode sites (3) and (4) ranged from 1.5 to $4.0 \mathrm{~mm}$. ventricular muscle attached at each end (Fig. 1). After dissection, the preparations were stored in cool oxygenated Tyrode solution until studied. Tyrode solution, gassed with $95 \%$ oxygen, $5 \%$ carbon dioxide, was infused into the perfusion chamber at constant rates of $8 \mathrm{ml} / \mathrm{min}$. Temperature was maintained at $36 \pm 1^{\circ} \mathrm{C}$. The composition of the Tyrode solution and the techniques used for stimulating and recording have been described previously $(19,22)$. The ionization of lidocaine is known to be dependent upon $\mathrm{pH}$. The $\mathrm{pH}$ of the Tyrode solution in the tissue bath under experimental conditions was measured and found to be $7.36 \pm 0.008$. At this $\mathrm{pH}, 25 \%$ of the drug should be in the basic and $75 \%$ in the cationic form. Powdered lidocaine hydrochloride was dissolved in distilled water and this solution was diluted with Tyrode solution to obtain the final concentrations; five different molar concentrations of lidocaine were routinely employed in these experiments: $1 \times 10^{-7}, 1 \times 10^{-8}, 1 \times 10^{-5}$, $5 \times 10^{-5}$, and $1 \times 10^{-4} \mathrm{~mole} / \mathrm{liter}(0.0234-23.4 \mu \mathrm{g} / \mathrm{ml})$. In a few experiments, concentrations up to $5 \times 10^{-4}$ mole/liter $(117 \mu \mathrm{g} / \mathrm{ml})$ were used. After control measurements, each preparation was exposed to the lowest of these concentrations $\left(1 \times 10^{-7} \mathrm{~mole} / \mathrm{liter}\right)$ for $30 \mathrm{~min}$. Measurements then were repeated and the next higher lidocaine concentration was employed. This sequence was repeated until the highest concentration ( 1 to $5 \times 10^{-4}$ mole/liter) was reached. Serial measurements up to $90 \mathrm{~min}$ after a change in lidocaine concentration indicated that a new steady state was reached in $20 \mathrm{~min}$ or less.

In most experiments, the preparations were arranged as shown in Fig. 1. The surface electrodes at site (1) were used to stimulate the ventricular muscle. The transmembrane potential of a nearby ventricular muscle cell was recorded using a microelectrode at site (4). A simultaneous recording of the action potential of an adjacent Purkinje fiber and its first time derivative was made through a second microelectrode at site (3). A pair of surface electrodes, placed on the Purkinje fiber (2), was used either to determine whether very premature action potentials propagated down the fiber from site (3) or to stimulate the Purkinje fiber directly during determination of the refractory period of ventricular muscle by the method of $\mathrm{Kao}$ and Hoffman (23).

This arrangement was used to determine the effective refractory period (ERP) of ventricular muscle and Purkinje fibers and the "membrane responsiveness" of the Purkinje fiber. The preparation was stimulated at a basic drive cycle length of $800 \mathrm{msec}(75 / \mathrm{min})$ and premature stimuli were then introduced every seventh drive cycle through surface electrodes at site (1). Action potentials were recorded at sites (3) and (4) (Fig. 1) and the propagation of premature Purkinje fiber responses verified by the surface electrogram recorded at site (2) of Fig. 1. The stimulus to the Purkinje fiber was the action potential of the adjacent ventricular muscle. Test stimuli initially were timed to fall late in diastole and then made progressively more premature until the earliest ventricular muscle action potential which induced a propagating action potential in the Purkinje fiber was determined. This measured the effective refractory period of the Purkinje fiber. Slightly earlier test stimuli still produced action potentials of large amplitude in ventricular muscle, however, these action potentials caused only a local response in the Purkinje fiber impaled at site (3) and did not propagate to site (2) (Fig. 1). Test stimuli then were made more premature until the ventricular muscle cell, impaled at site (4) (Fig. 1), failed to respond. This determined the effective refractory period of ventricular muscle. 
Measuring the maximum rate of $\mathrm{PF}$ phase 0 depolarization $\left(\mathrm{V}_{\max }\right)$ of each premature action potential by electronic differentiation (19) during these stimulation sequences allowed the determination of membrane responsiveness, the relationship between $V_{m \times x}$ and the transmembrane activation voltage (MAV) at the time of $\mathrm{PF}$ excitation.

\section{RESULTS}

Effect of lidocaine on transmembrane voltage characteristics

Purkinje fibers. In 15 preparations under control conditions, the maximum diastolic transmembrane voltage $\left(D_{T M V} \max \right)$ in Purkinje fibers was $92.4 \pm 0.45$ $\mathrm{mv}$ (mean SEM $_{\text {) }}$ and the action potential overshoot $32.1 \pm 0.63 \mathrm{mv}$, the total amplitude of the action potential being $124.5 \pm 1.06 \mathrm{mv}$. At concentrations between $1 \times 10^{-7}$ and $5 \times 10^{-6}$ mole/liter, lidocaine exerted no significant effect on DTMV $\max$, overshoot, or total action potential amplitude. At $1 \times 10^{-4}$ mole/liter, the results were variable; the action potential amplitude recorded from some fibers remained unchanged, others showed decreases in both $D T M V_{\max }$ and overshoot. At this concentration, the decreases of $\mathrm{DTMV}_{\max }$ to 90.8 $\pm 0.45 \mathrm{mv}(P<0.01)$, action potential overshoot to $29.1 \pm 0.59 \mathrm{mv}(P<0.001)$, and total action potential amplitude to $119.8 \pm 1.04 \mathrm{mv}(P<0.001)$ were significant.

When fibers were exposed to concentrations of lidocaine near $5 \times 10^{-4}$ mole/liter, there was a uniform marked decrease in $D T M V_{\max }$ and overshoot and bizarre alterations in depolarization ensued (see Fig. 2). Shortly after exposure to this concentration, depolarization became a discontinuous two phase process and the fiber usually became inexcitable in 15-30 min (see Fig. 2).

For reasons to be discussed further, we assumed that lidocaine concentrations from $1 \times 10^{-5}$ to $5 \times 10^{-5} \mathrm{~mole} /$ liter were roughly comparable with therapeutic concentrations in man. Concentrations $\geq 1 \times 10^{-4}$ mole/liter were thought to be toxic.

Lidocaine caused shortening of Purkinje fiber action potentials over a wide range of drug concentration (15 preparations) and frequencies of stimulation (12 preparations). This lidocaine-induced action potential shortening was often pronounced, as shown in Fig. 3, which shows that at a drive cycle length of $1000 \mathrm{msec}(60 / \mathrm{min})$ and at a lidocaine concentration of $1 \times 10^{-4} \mathrm{~mole} / \mathrm{liter}$, the Purkinje fiber action potential shortened $220 \mathrm{msec}$ from control (a $40 \%$ decrease). This acceleration of repolarization was produced by a shortening of phase 2 , a slight increase in the slope of phase 2 , and, at concentrations up to $5 \times 10^{-5} \mathrm{~mole} / \mathrm{liter}$, to an increase in the slope of phase 3. At concentrations above $5 \times 10^{-5}$ mole/liter, the results were variable; in some fibers, the shape of action potential repolarization became con- cave upward making it difficult to distinguish the usual phases of repolarization (see Fig. 3), and in others,
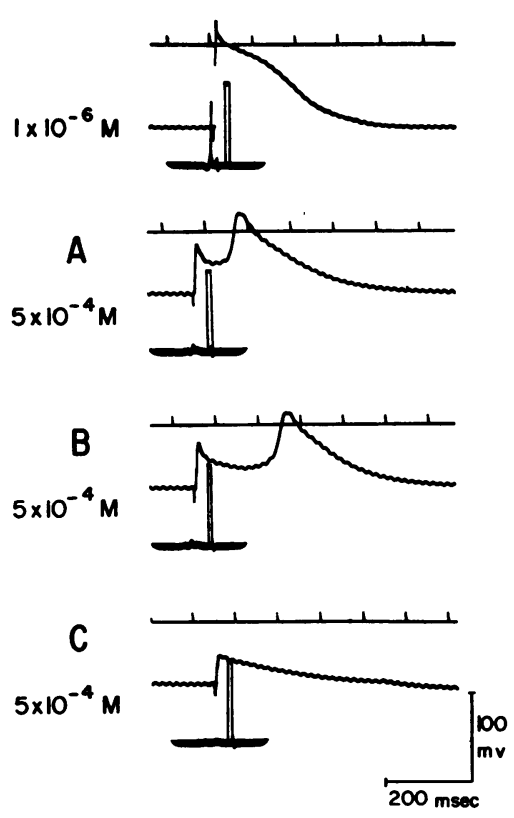

Figure 2 Effect of a toxic concentration of lidocaine $\left(5 \times 10^{-4}\right.$ mole/liter, $\left.117 \mu \mathrm{g} / \mathrm{ml}\right)$ on a canine Purkinje fiber. The upper trace in each panel represents the zero potential base line on which time markers are recorded every 100 msec, the center trace records the Purkinje fiber (PF) transmembrane potential and the lower trace records the first time derivatives of the action potential upstroke (left) and a $500 \mathrm{v} / \mathrm{sec}$ calibration pulse (right). The upper panel shows the PF after a $30 \mathrm{~min}$ exposure to $1 \times 10^{-6} \mathrm{M}$ lidocaine. At this concentration, the action potential depolarization was not changed from control values. Resting potential was $-94 \mathrm{mv}$ and peak $V_{\max } 445 \mathrm{v} / \mathrm{sec}$. The lower three panels, labeled $\mathrm{A}, \mathrm{B}$, and $\mathrm{C}$ were obtained 20,25 , and 30 min after beginning perfusion with $5 \times 10^{-4} \mathrm{M}$ lidocaine. Note that in $A$, the resting potential has decreased to $-72 \mathrm{mv}$, depolarization has separated into two phases, and the action potential duration (APD) has become greatly prolonged. The initial phase of depolarization is slowed to $25 \mathrm{v} / \mathrm{sec}$ and the membrane voltage only reaches $-15 \mathrm{mv}$ and then declines to a steady potential of $-35 \mathrm{mv} .86 \mathrm{msec}$ later, a second phase of depolarization occurs and the transmembrane voltage reaches a maximum positive value of +19 mv. Repolarization, after the second depolarization, was slow. The time taken to fully recover resting potential was approximately $450 \mathrm{msec}$. Panel $\mathrm{B}$ shows the PF transmembrane potential, $5 \mathrm{~min}$ after the recording in panel A. The resting potential remains $-72 \mathrm{mv}$ and the transmembrane voltage attained by each of the two phases of depolarization is similar to those recorded in panel A. By this time, the delay between the two phases of depolarization increased to $183 \mathrm{msec}$, a change of $97 \mathrm{msec}$. Panel C shows the $\mathrm{PF}$ transmembrane potential $5 \mathrm{~min}$ after the recording in panel $\mathrm{B}$. Although the resting potential still remains at -72 $\mathrm{mv}$, the fiber is essentially inexcitable; electrical stimuli are followed by an abortive membrane depolarization to -36 $\mathrm{mv}$, the same voltage as the steady voltage previously noted between the two phases of depolarization.

Lidocaine and Cardiac Membrane Potentials 
shortening occurred without this change in shape (see Fig. 6). The marked effects on action potential duration (APD) and configuration were reversible within 20-60 min after removing lidocaine from the perfusate.

The effect of lidocaine on PF APD was examined over a wide range of drive cycle lengths; the results obtained in 12 experiments are plotted in Fig. 4. The absolute shortening in APD was greater at longer drive cycle lengths, but there was little difference in the per cent change at any given cycle length. For example, at a concentration of $1 \times 10^{-5}$ mole/liter, APD decreased by $15 \pm 3 \%$ at every drive cycle length. Fig. 4 also demonstrates the tendency for PF APD to be longer at a lidocaine concentration of $1 \times 10^{-4}$ mole/liter than at lower concentrations. This increase in duration was usually due to prolonged terminal repolarization which resulted from a decrease in slope $(\mathrm{dv} / \mathrm{dt})$ of repolarization as membrane potential approached DTMV $\max$ (see Fig. 3).

In Fig. 5, the PF APD for 15 fibers is plotted as a function of lidocaine concentration at a drive cycle length of $800 \mathrm{msec}$. The APD in PF shortened from a mean of $352 \pm 12$ msec under control conditions to 325 $\pm 12 \mathrm{msec}$ after exposure to $1 \times 10^{-7} \mathrm{M}$ lidocaine $(P<$ $0.05)$ and reached a minimum of $298 \pm 9 \mathrm{msec}$ at a $1 \times$ $10^{-5} \mathrm{M}$ lidocaine concentration $(P<0.001)$. At a $1 \times$ $10^{-4} \mathrm{M}$ concentration of lidocaine, the mean APD was $306 \pm 12 \mathrm{msec}$, longer than at $5 \times 10^{-5} \mathrm{~mole} / \mathrm{liter}$, but

\section{1000}

CONTROL

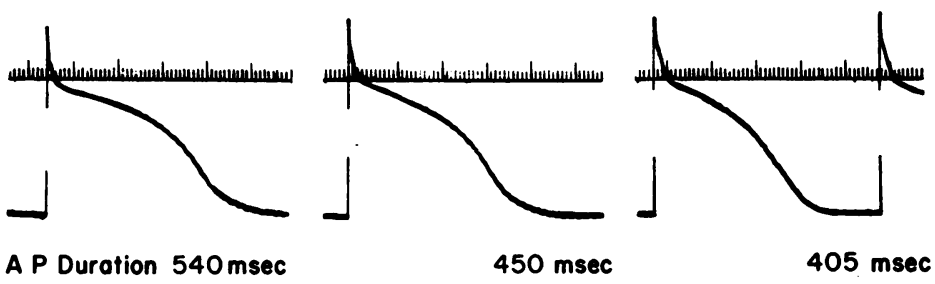

$1 \times 10^{-5} \mathrm{~m}$

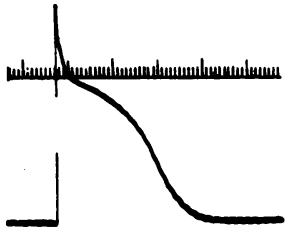

A P Duration $350 \mathrm{msec}$

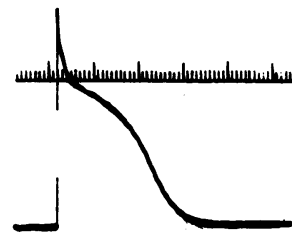

$340 \mathrm{msec}$

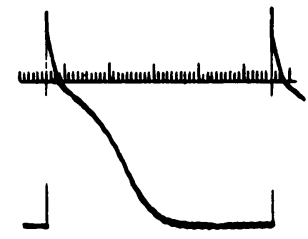

$312 \mathrm{msec}$

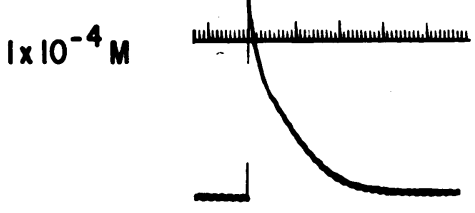

A P Duration $320 \mathrm{msec}$

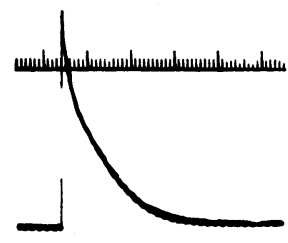

$310 \mathrm{msec}$
$200 \mathrm{msec}$

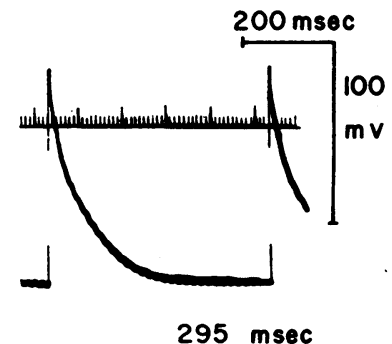

295 msec

FIgURE 3 The effect of lidocaine on the action potential duration of a canine Purkinje fiber. In each panel, the top trace records time markers which recur at 10 -msec intervals. The lower trace records the transmembrane potential of the PF. A time calibration of $200 \mathrm{msec}$ and a voltage calibration of $100 \mathrm{mv}$ are shown in the lower right of the figure. The top row shows the action potentials recorded under control conditions with the fiber driven electrically (left to right) at cycle lengths of $1000(60 / \mathrm{min}), 800(75 / \mathrm{min})$, and $500 \mathrm{msec}(120 / \mathrm{min})$. The APD's were 540, 450, and $405 \mathrm{msec}$, respectively. The second row of action potentials was recorded from the same cell after it had been exposed to lidocaine for $30 \mathrm{~min}$ at a concentration of $1 \times 10^{-5} \mathrm{~mole} / \mathrm{liter}(2.34 \mu \mathrm{g} / \mathrm{ml})$. At the same drive cycle lengths of 1000 , 800 , and $500 \mathrm{msec}$, the APD's were 350,340 , and $312 \mathrm{msec}$. The lowest row of action potentials was recorded from the same cell after $30 \mathrm{~min}$ of exposure to lidocaine in a concentration of $1 \times 10^{-4} \mathrm{~mole} /$ liter $(23.4 \mu \mathrm{g} / \mathrm{ml})$. The APD's at drive cycle lengths of 1000,800 , and $500 \mathrm{msec}$ were 320,310 , and $295 \mathrm{msec}$. 
still significantly shorter than control values $(P<0.01)$. At $1 \times 10^{-4}$ mole/liter, the variability in APD between the individual fibers was greater; in most studies, APD was longer at $1 \times 10^{-4}$ than at $5 \times 10^{-6} \mathrm{~mole} / \mathrm{liter}$, but a few were shorter at the higher concentration.

Ventricular muscle. In 10 preparations, the control ventricular muscle action potential amplitude was 108.3 $\pm 3.40 \mathrm{mv}$ (mean \pm SEM) with a resting transmembrane voltage of $88.8 \pm 0.49 \mathrm{mv}$ and an overshoot of $19.5 \pm 2.17$ mv. These variables, like those in Purkinje fibers, were not significantly altered by lidocaine until a concentration of $1 \times 10^{-4} \mathrm{~mole} / \mathrm{liter}$ was reached. At this concentration, action potential amplitude fell to $104.8 \pm 0.92 \mathrm{mv}(P<$ 0.001 ) due to a small decrease in resting voltage to 88.1 $\pm 0.35 \mathrm{mv}(P<0.05)$ and a more strik:ng decrease in

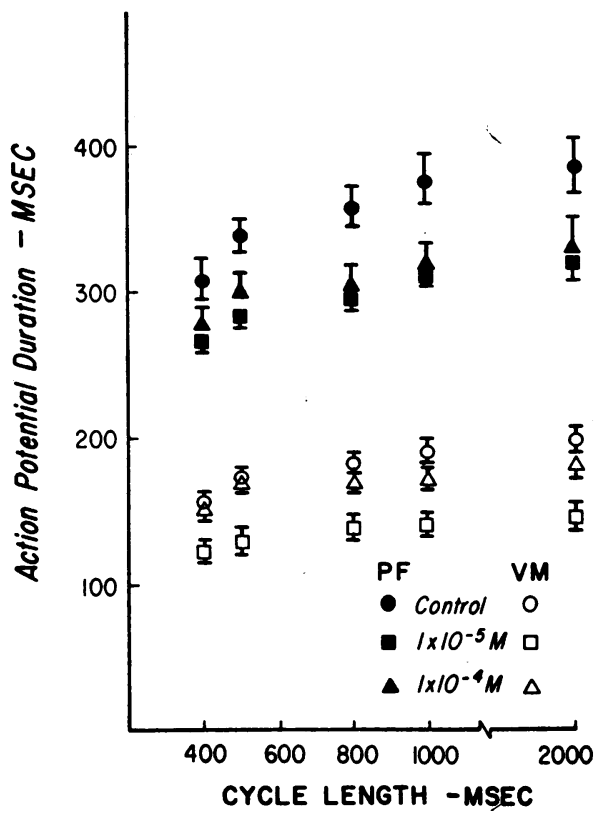

FIgURE 4 The duration of the action potential (mean $\pm_{\text {SEM }}$ ) of 12 Purkinje fibers (above, filled symbols) and 7 ventricular muscle fibers (below, unfilled symbols) as a function of the driven cycle length. Observations are shown for control conditions (circles), and during exposure to lidocaine at concentrations of $1 \times 10^{-5} \mathrm{~mole} /$ liter (squares) and $1 \times 10^{-4}$ mole/liter (triangles). APD of both $\mathrm{PF}$ and ventricular muscle (VM) fibers were recorded at drive cycle lengths of $400,500,800,1000$, and $2000 \mathrm{msec}$. After exposure to $1 \times 10^{-5} \mathrm{M}$ lidocaine, the PF APD shortened significantly at each drive rate $(P<0.001$, at every cycle length). After exposure to a toxic concentration of lidocaine $\left(1 \times 10^{-4} \mathrm{~mole} /\right.$ liter), the mean APD became longer than that seen at a concentration of $1 \times 10^{-5} \mathrm{~mole} /$ liter but was still significantly shorter than the APD recorded under control conditions ( $P<0.01$, at every cycle length). V.M fiber APD also shortened significantly $(P<0.001)$ at the $1 \times 10^{-5}$ concentration. At a $1 \times 10^{-4}$ M concentration, however, the VM APD is significantly shorter than control only at drive cvcle lengths of $800 \mathrm{msec}$ or longer $(P<0.05)$.

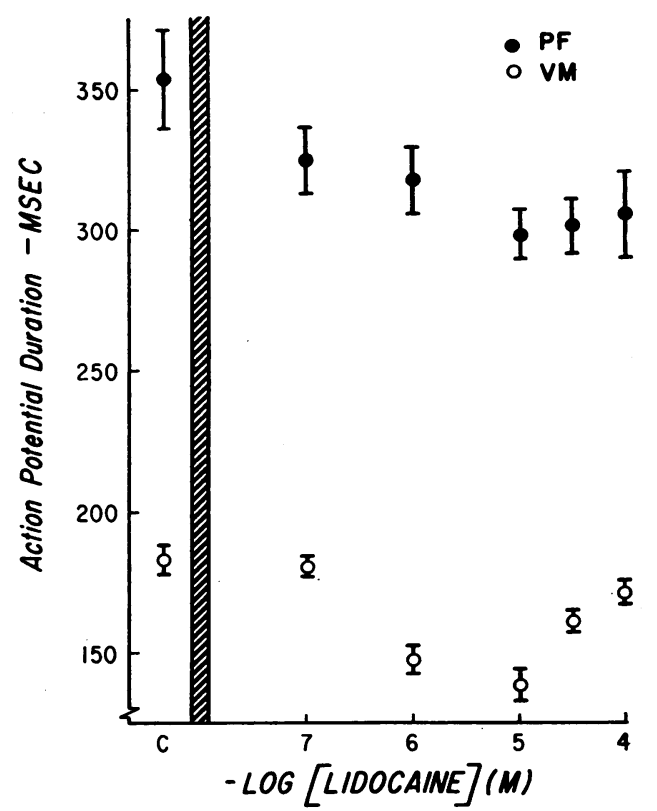

Figure 5 Purkinje and ventricular muscle fiber action potential duration as a function of the lidocaine concentration. All observations were obtained at a drive cycle length of $800 \mathrm{msec}(75 / \mathrm{min})$. APD in milliseconds is plotted on the ordinate, and the negative common logarithm of lidocaine concentration is plotted on the abscissa. Control observations (C) (PF, n = 15 and VM, $n=8)$ are plotted to the left of the hatched bar. Values for PF (filled circles) and VM (unfilled circles) are plotted as the mean \pm SEM. At a $1 \times 10^{-}$ M lidocaine concentration, APD shortening was significant only in $\mathrm{PF}(P<0.05)$. At all higher concentrations, the mean APD of both VM and PF was significantly shorter than control values $(P<0.01$ in every case except for $\mathrm{PF}$ at $1 \times 10^{-4}$ mole/liter, where $P<0.05$ ).

overshoot to $16.8 \pm 0.61 \mathrm{mv}(P<0.001)$. Two muscle fibers studied at $1 \times 10^{-4} \mathrm{~mole} / \mathrm{liter}$ and four of five studied at $5 \times 10^{-4} \mathrm{~mole} /$ liter showed large decreases in resting voltage and action potential amplitude with fragmentation of phase 0 depolarization into two components (see Fig. 6).

The action potential duration of ventricular muscle fibers was also shortened by lidocaine. When the preparation shown in Fig. 6 was driven at a cycle length of $1000 \mathrm{msec}$, the action potential in VM shortened by 36 msec during exposure to $1 \times 10^{-5} \mathrm{M}$ lidocaine (a decrease of $18 \%$ ) and by $22 \mathrm{msec}$ at $1 \times 10^{-4}$ mole/liter (a decrease of $11 \%$ from control).

Shortening of APD after lidocaine also varied as a function of drive cycle length in all seven ventricular muscle fibers studied (see Figs. 4 and 6). Action potentials shortened more at longer cycle lengths where the control APD was longer, but the per cent change in APD at each cycle length again was virtually identical at any given lidocaine concentration. For instance, at

Lidocaine and Cardiac Membrane Potentials 
$1 \times 10^{-5}$ mole/liter, the mean per cent shortening from control, at the five stimulation cycle lengths shown in Fig. 4, ranged from $-22.4 \pm 3.3 \%$ to $-27.0 \pm 3.0 \%$ (in each case, $P<0.001$ ). It is also apparent in Fig. 4 that, at a concentration of $1 \times 10^{-4}$ mole/liter, the APD at any given drive cycle length was longer than it had been at $1 \times 10^{-5}$ mole/liter. This lengthening of APD at the $1 \times 10^{-4} \mathrm{M}$ concentration was much more prominent in $V M$ than in $P F$.

In Fig. 5, VM APD is plotted as a function of lidocaine concentration for eight fibers stimulated at a constant 800 msec cycle length. No significant change from the control value of $183 \pm 10 \mathrm{msec}$ was noted at a $1 \times$ $10^{-7} \mathrm{M}$ concentration. At $1 \times 10^{-6} \mathrm{~mole} / \mathrm{liter}$, the mean shortening of $39.9 \pm 4.3 \mathrm{msec}$ (a $22 \%$ decrease) was highly significant $(P<0.001)$. Maximum change was seen at $1 \times 10^{-5}$ mole/liter where the mean VM APD was shortened $41.7 \pm 4.7 \mathrm{msec}$. The ascending limb of the APD-concentration curve was more prominent for ventricular muscle fibers than Purkinje fibers; at $1 \times 10^{-4}$ mole/liter, APD had again increased to $171 \pm 8 \mathrm{msec}$.

All changes induced by lidocaine concentrations up to $1 \times 10^{-4}$ mole/liter in both ventricular muscle and Purkinje fibers were reversed within $20-60 \mathrm{~min}$ by reinstituting perfusion with drug-free Tyrode solution.

Effect of lidocaine on the duration of the effective refractory period

Purkinje fiber. The ERP of Purkinje fibers was measured in the control state and after exposure to lidocaine in eight experiments (see Figs. 7 and 8). A typical record is shown in Fig. 7. The lower row shows the determination of PF ERP before and after exposure to lidocaine. In this instance, the PF ERP shortened 46 msec during exposure to $5 \times 10^{-6} \mathrm{M}$ lidocaine and 28 msec during exposure to a $1 \times 10^{-4}$ M concentration.
CL 2000

CONTROL

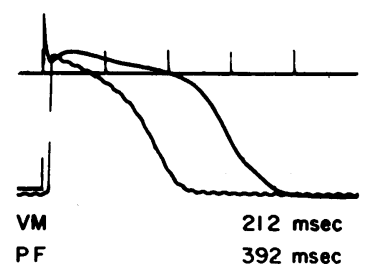

$1 \times 10^{-5} \mathrm{M}$

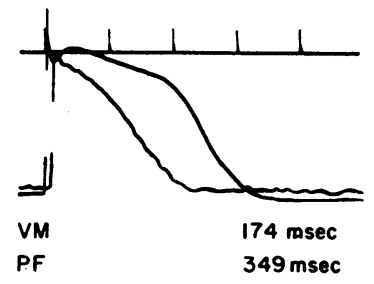

$1 \times 10^{-4} \mathrm{M}$

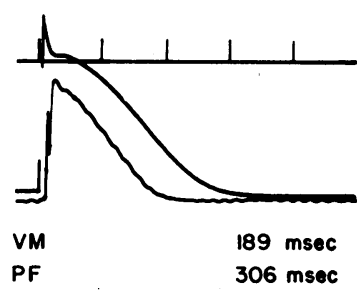

CL 1000
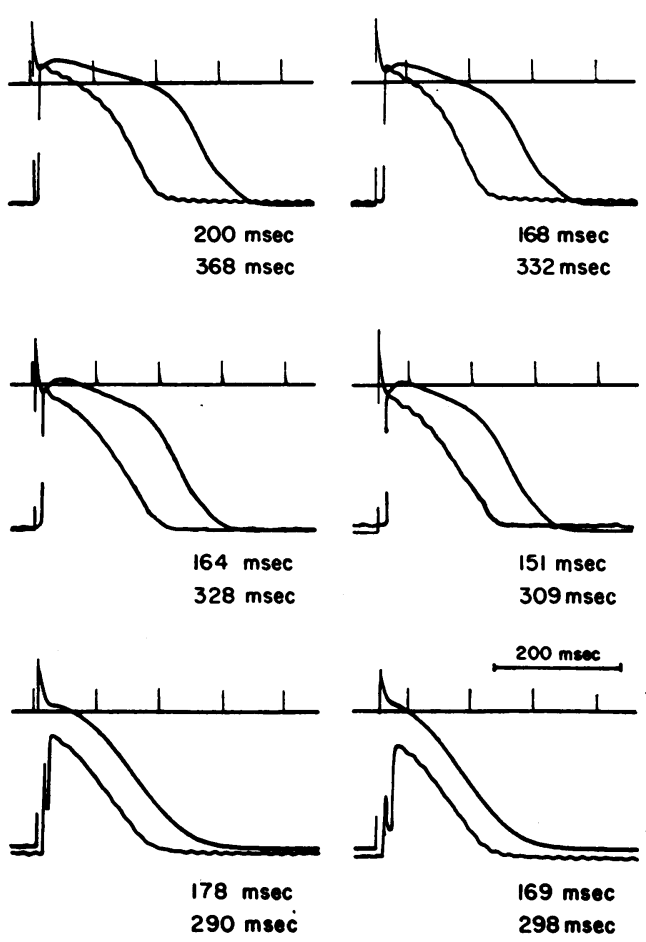

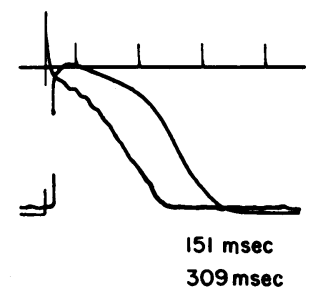

CL 500

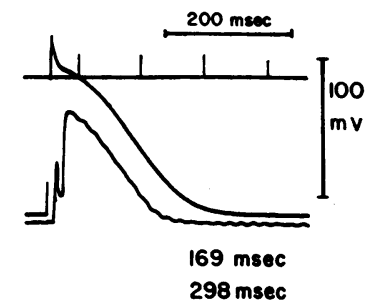

FIGURE 6 The effect of lidocaine on the transmembrane potentials of Purkinje and ventricular muscle fibers. Recordings taken at drive cycles (CL) of 2000,1000 , and $500 \mathrm{msec}$ are shown under control conditions (top row) during exposure to lidocaine at $1 \times 10^{-5}$ mole/liter (middle row), and $1 \times 10^{-4}$ mole/liter (bottom row). Time marks recur every $100 \mathrm{msec}$ on the top trace in each panel. The APD in milliseconds of the VM and the PF are given under each panel. Shortening of the PF APD at $1 \times 10^{-5}$ mole/liter is achieved without significant alteration in configuration, phase 2 is merely shortened. At $1 \times 10^{-4}$ mole/liter, the PF APD shows profound configurational change, i.e., further shortening of phase 2 and a decrease in the slope of both phase 3 and terminal repolarization. The APD of $\mathrm{VM}$ shortened at $1 \times 10^{-5}$ but was less shortened at $1 \times 10^{-4} \mathrm{~mole} / \mathrm{liter}$. At the higher toxic concentration, two compcnents of depolarization develop (see Fig. 5). 
The PF ERP is plotted as a function of lidocaine concentration for all experiments in Fig. 8. There was a significant decrease in PF ERP even at $1 \times 10^{-7} \mathrm{~mole} /$ liter where the mean ERP fell to $238 \pm 12 \mathrm{msec}$ from the mean control value of $274 \pm 17(P<0.025)$. The mean ERP reached a minimum at $1 \times 10^{-6}$ and $1 \times 10^{-5} \mathrm{M}$ concentrations where values of $228 \pm 13$ and $231 \pm 16$ msec were found. In Purkinje fibers, the ERP-concentration curve differed significantly from the APD-concentration curve in that the ERP-concentration curve

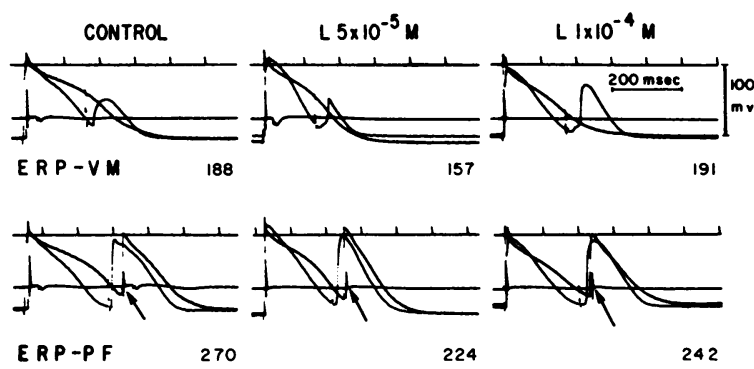

FIGURE 7 Effect of lidocaine on the effective refractory period of ventricular muscle and an adjacent Purkinje fiber. The stimulating and recording arrangement used is shown in Fig. 1. In each panel, the upper trace records time marks every $100 \mathrm{msec}$. The remaining three traces record the VM and $\mathrm{PF}$ action potentials (from sites 3 and 4, Fig. 1) and the PF surface electrogram (site 2, Fig. 1). The upper row of panels shows the most premature VM action potential obtainable (recorded at site 4, Fig. 1). This minimum interval between driven $\left(\mathrm{VM}_{1}\right)$ and premature $\left(\mathrm{VM}_{2}\right)$ responses measures the effective refractory period (ERP) of VM. Under control condition, the ERP (minimum $\mathrm{VM}_{1}$ $\mathrm{VM}_{2}$ ) of ventricular muscle was $188 \mathrm{msec}$. During exposure to lidocaine, $5 \times 10^{-5}$ mole/liter, the ERP of VM shortened to $157 \mathrm{msec}$, and during perfusion with a $1 \times 10^{-4} \mathrm{M}$ concentration, the ERP lengthened to $191 \mathrm{msec}$. It should be noted that the duration of action potentials recorded from VM shortened after exposure to lidocaine. The control APD of the VM cell was $203 \mathrm{msec}$, that at $5 \times 10^{-5} \mathrm{M}$ lidocaine 161 $\mathrm{msec}$, and that at $1 \times 10^{-4} \mathrm{M}$ lidocaine $183 \mathrm{msec}$. The three panels in the lower row show the ERP of the PF (recorded from site 3 , Fig. 1). These recordings were made at the shortest $\mathrm{VM}_{1} \mathrm{VM}_{2}$ interval which produced propagating action potentials in the $\mathrm{PF} . \mathrm{VM}_{2}$ not only produced an action potential at the nearby $\mathrm{PF}$ microelectrode recording site (site 3, Fig. 1) but also propagated down the PF as shown by the electrogram recorded from site 2 (see Fig. 1); the arrow in each panel in the lower row points to the surface electrogram deflection. Under control conditions, the PF ERP was $270 \mathrm{msec}$. The ERP shortened to $224 \mathrm{msec}$ during exposure to $5 \times 10^{-5} \mathrm{M}$ lidocaine. During exposure to a $1 \times$ $10^{-t} \mathrm{M}$ concentration, the ERP was $242 \mathrm{msec}$, longer than that seen during perfusion with $5 \times 10^{-5} \mathrm{M}$ lidocaine but still much shorter than control values. The PF APD was 358 msec under control conditions, $310 \mathrm{msec}$ at $5 \times 10^{-5}$, and 307 msec at $1 \times 10^{-4} \mathrm{M}$ lidocaine. These recordings also demonstrate that after lidocaine: $(a)$ the time difference in APD of VM and the adjacent PF diminished, and $(b)$ the time required for a very premature $\mathrm{VM}_{2}$ to propagate to the recording site on the $\mathrm{PF}$ was reduced, i.e., the $\mathrm{VM}_{2} \mathrm{PF}_{2}$ interval decreased.

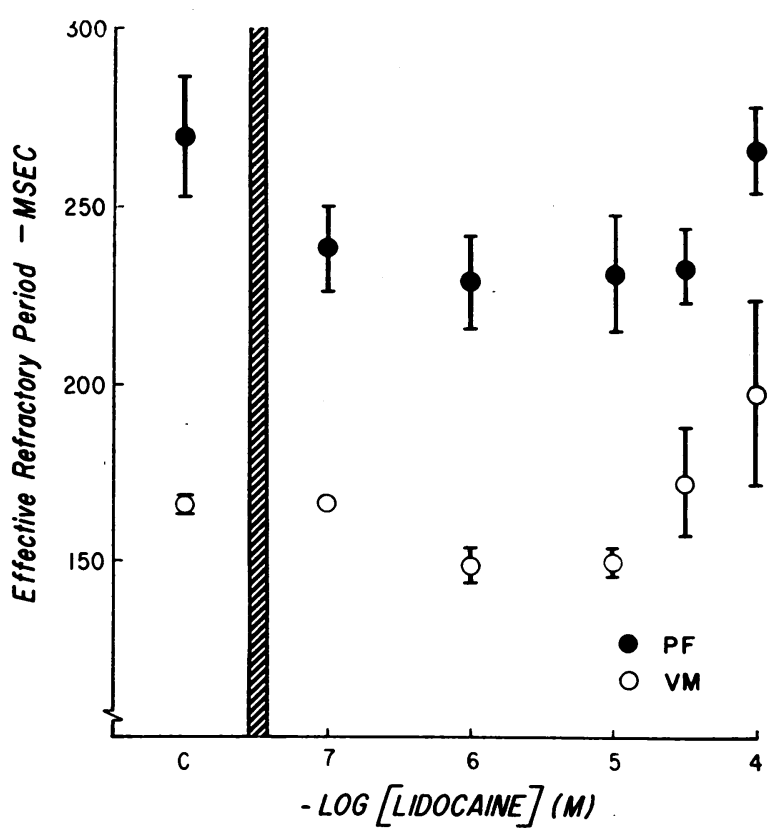

FIgURE 8 Effective refractory period of Purkinje fibers and ventricular muscle as a function of lidocaine concentration. All observations plotted were obtained at a cycle length of $800 \mathrm{msec}(75 / \mathrm{min})$. ERP in msec is plotted on the ordinate and the negative common logarithm of lidocaine concentration is plotted on the abscissa. Control observations (C) ( $P F, n=8$ and VM, $n=8$ ) are plotted to the left of the hatched bar. Values for Purkinje fibers (filled circles) are plotted as the mean \pm SEM. Note that the decrease of ERP from the control of $269 \pm 17$ to $238 \pm 12$ after exposure to a $1 \times 10^{-7} \mathrm{M}$ concentration of lidocaine is significant $(P<$ $0.025)$. There was little further change in the ERP when preparations were exposed to concentrations of lidocaine from $1 \times 10^{-6}$ to $5 \times 10^{-5}$ mole/liter $(P<0.025$ in each instance). In the presence of a $1 \times 10^{-4} \mathrm{M}$ concentration, the mean ERP prolonged to $266 \pm 12$, a value not significantly different from the mean control ERP. Although the ERP became long again after $1 \times 10^{-4} \mathrm{M}$ lidocaine, the mean $\mathrm{PF}$ APD at this concentration was still significantly shorter than control (see Fig. 4). Experimental observations for VM (unfilled circles) are plotted as the mean \pm SEM. Only at lidocaine concentrations of $1 \times 10^{-6}$ and $1 \times 10^{-5} \mathrm{~mole} / \mathrm{liter}$ was there any significant decrease in the ERP of VM $(P<$ 0.05 in each instance). At $5 \times 10^{-5}$ mole/liter the mean ERP was identical with control and at $1 \times 10^{-4}$ mole/liter $15 \%$ greater than control, but the variation between experiments at this concentration is apparent from standard error bars.

had a definite ascending limb. The ERP did, however. remain significantly shorter than control until $1 \times 10^{-4}$ mole/liter was employed; at this concentration, the mean PF ERP was $266 \pm 12 \mathrm{msec}$, a value not significantly different from control $(P<0.1)$. It should be emphasized that at this concentration $\left(1 \times 10^{-4}\right.$ mole/ liter), the PF APD remained significantly shorter than control.

Lidocaine and Cardiac Membrane Potentials 
Although the Purkinje fiber shown in Fig. 7 had an ERP shorter than control at both $5 \times 10^{-5}$ and $1 \times 10^{-4} \mathrm{M}$ lidocaine concentrations, the transmembrane voltage at which the most premature propagating response could be elicited was increased after application of lidocaine. Note that in Fig. 7, transmembrane voltage at the time of earliest premature activation was $69 \mathrm{mv}$ under control conditions, $75 \mathrm{mv}$ during exposure to lidocaine $5 \times 10^{-5} \mathrm{~mole} / \mathrm{liter}$, and $78 \mathrm{mv}$ at $1 \times 10^{-4} \mathrm{~mole} / \mathrm{liter}$. Thus the action potential shortened more than the ERP at these lidocaine concentrations (see Fig. 9 A). These very premature responses were only elicited at higher transmembrane voltages and therefore had higher amplitudes than the early premature responses before lidocaine. The changes at $5 \times 10^{-5}$ mole/liter were not ac- companied by a reduction in membrane responsiveness (vide infra).

Ventricular muscle. The effect of lidocaine on the ERP of ventricular muscle, measured in the same eight experiments, was qualitatively similar to the findings for Purkinje fibers. The upper row of panels in Fig. 7 shows that exposure to $5 \times 10^{-5} \mathrm{M}$ lidocaine shortened VM ERP by $31 \mathrm{msec}$. However, at $1 \times 10^{-4}$ mole/liter the VM ERP was not only longer than that found at $5 \times 10^{-5}$ mole/liter but also exceeded the control value. The mean VM ERP for all experiments is plotted as a function of the lidocaine concentration in the lower part of Fig. 8. Significant shortening of the ERP was seen only at $1 \times 10^{-6}$ and $1 \times 10^{-5} \mathrm{~mole} /$ liter $(P<0.05$, in each case). At $5 \times 10^{-5}$ mole/liter, VM ERP was

\section{$A(P F)$}

\section{$\triangle$ ERP MSEC}

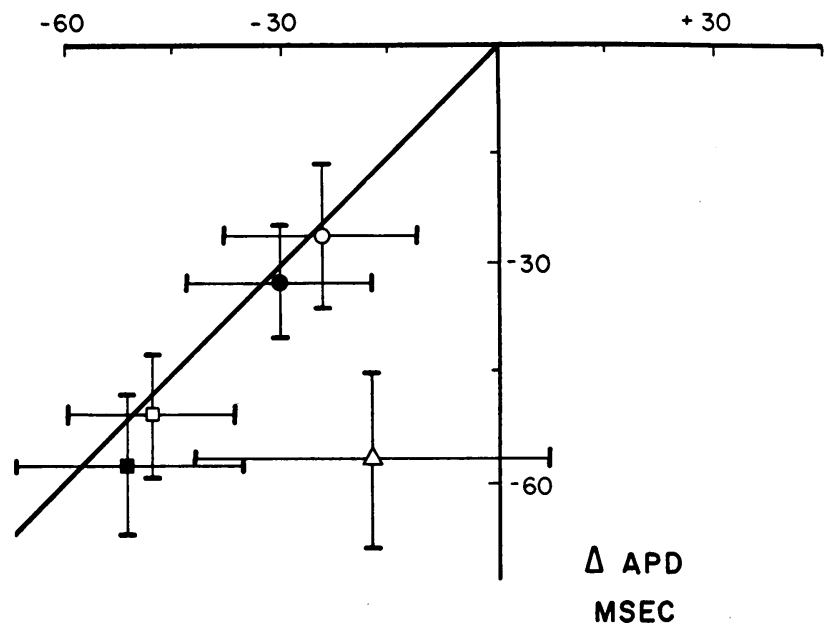

$B(V M)$

$\triangle$ ERP MSEC

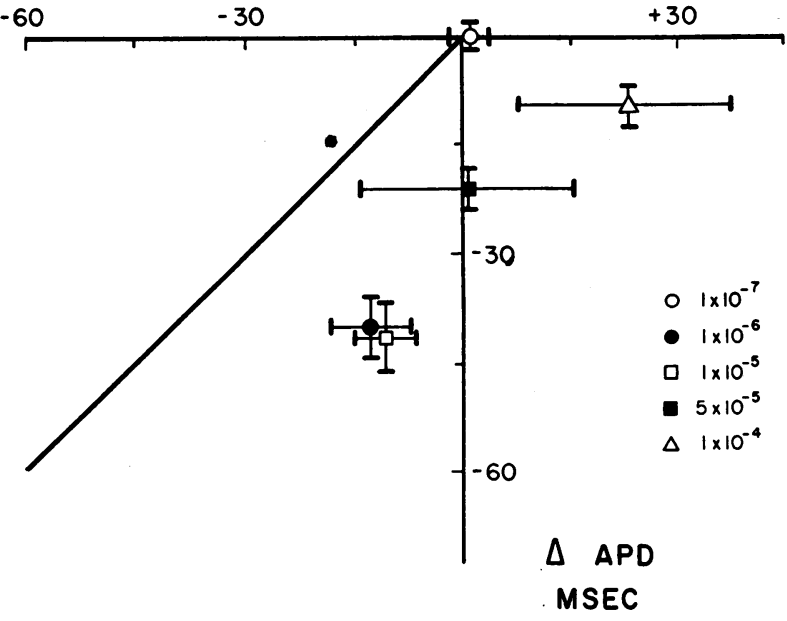

FIGURE 9 The change in action potential duration ( $\triangle \mathrm{APD}$ ) relative to change in effective refractory period $(\triangle E R P)$ in both PF and VM fibers is shown as a function of lidocaine concentration. The mean $\triangle \mathrm{APD}$ in milliseconds is plotted on the ordinate and the mean $\triangle E R P$ in milliseconds on the abscissa in each panel. Lidocaine concentrations from $1 \times 10^{-7}$ to $1 \times 10^{-4}$ mole/liter are represented by the symbols shown in the key (panel B). The diagonal line in panels $A$ and $B$ is the line of identity on which each symbol would be if the mean $\triangle A P D$ and mean $\triangle E R P$ were equal at any given lidocaine concentration. In panel $\mathrm{A}$, each symbol represents the mean change in 12 experiments performed on $\mathrm{PF}$ at the given lidocaine concentration. At concentrations of $1 \times 10^{-7}$ to $1 \times 10^{-5} \mathrm{M}$ lidocaine, there is a progressive and almost equal shortening of both the mean $\triangle \mathrm{APD}$ and mean $\triangle \mathrm{ERP}$. A maximum change in each variable (approximately $-37 \mathrm{msec}$ ) was reached at $1 \times 10^{-6} \mathrm{~mole} / \mathrm{liter}$, however at $1 \times 10^{-4} \mathrm{M}$ lidocaine, the $\triangle \mathrm{APD}$ was greater than the $\triangle \mathrm{ERP}$ causing the symbols to fall away from the line of identity. In panel $\mathrm{B}$, each symbol represents the mean change in seven experiments done on VM. Observations made at $1 \times 10^{-7}$ mole/liter showed no change from control values. All higher concentrations fall far off the line of identity, indicating that shortening of ERP was much less than shortening in APD in VM over a wide range of lidocaine concentration. The $\triangle E R P$ at $5 \times 10^{-5} \mathrm{M}$ concentration was nearly 0 when the $\triangle A P D$ was still $-21 \mathrm{msec}$. At $1 \times 10^{-4} \mathrm{M}$ concentration, the $\triangle \mathrm{APD}$ was not significantly different from control, and the $\triangle E R P$ had become significantly longer than control. See text for discussion. 
not significantly different from control, and at $1 \times 10^{-*}$ mole/liter, the mean VM ERP was longer than control values. The VM ERP became long relative to the VM APD during lidocaine exposure (see Fig. 9). The change in this relationship between APD and ERP was more marked in ventricular muscle than in Purkinje fibers.

It should be noted that changes in ERP duration in Purkinje and ventricular muscle fibers was reversible with the same time course as the reversal of changes in APD.

Effect of lidocaine on velocity of depolarization and membrane responsiveness

Under control conditions, the $V_{\max }$ elicited at the maximum diastolic transmembrane voltage was $538 \pm 16$ $\mathrm{v} / \mathrm{sec}$ (mean $\pm \mathrm{SEM}$ ) for 15 Purkinje fibers driven at
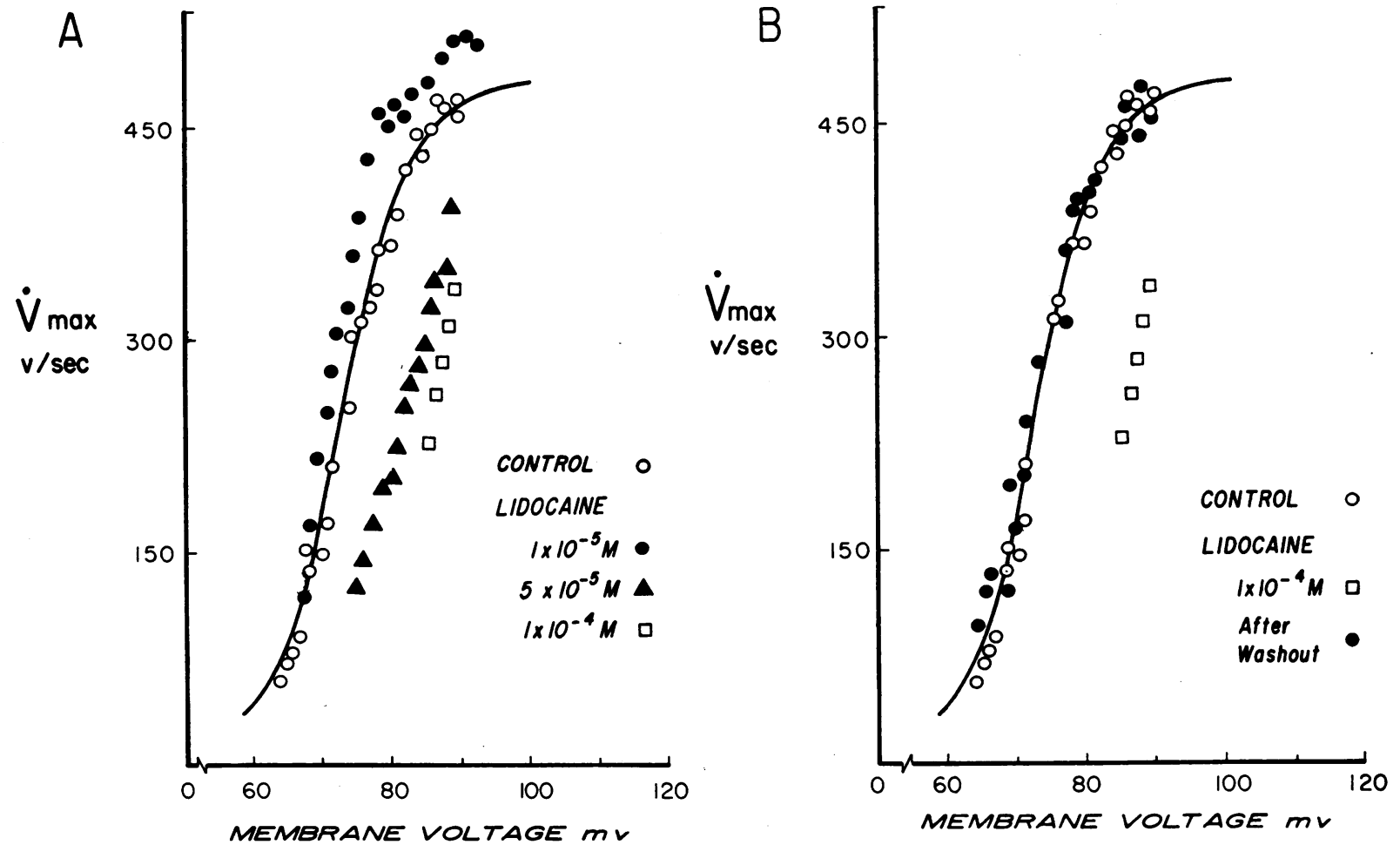

FIGURE 10. (A) An example of the effect of lidocaine on the "membrane responsiveness" of a canine Purkinje fiber. PF responses to stimuli delivered at selected times during the course of repolarization were recorded. Transmembrane voltage at the time of activation and the maximum rate of rise of phase $0\left(V_{\max }\right)$ of the subsequent action potential were thus recorded over a wide range of membrane voltage. Membrane voltage at the time of activation is plotted on the abscissa. The $\nabla_{\max }$ in volts per second is plotted on the ordinate. Each symbol in the graph represents the mean of at least three determinations. The curved line is computed for the control data by the formula of Weidermann (24). Unfilled circles are experimental points obtained under control conditions. Filled circles are observations made after the fiber has been exposed to a $1 \times 10^{-5} \mathrm{M}$ lidocaine concentration. At this concentration, the relationship was not greatly altered, although the peak $\nabla_{\max }$ was increased and the curve relating $\nabla_{\max }$ to $\mathrm{MP}$ was steeper. At a $5 \times 10^{-5} \mathrm{M}$ lidocaine concentration (filled triangles), the peak $V_{\max }$ was depressed in this fiber and the curve shifted to the right and downward. A further increase in lidocaine concentration to $1 \times 10^{-4}$ mole/liter resulted in further depression of peak $\nabla_{\max }$ and further rightward shift in the curve. See text for further discussion. (B) The reversibility of lidocaine-induced depression of "membrane responsiveness" in Purkinje fiber. These observations were made in the same cell from which data was shown in part A. The control observations (unfilled circles), the observations made after $1 \times 10^{-4} \mathrm{M}$ lidocaine (toxic) (unfilled squares), and the computed curve have been replotted. After the measurements were made during exposure to $1 \times 10^{-4}$ M lidocaine, the fiber was perfused with drug-free Tyrode solution. Measurements were made $1 \mathrm{hr}$ later (filled circles). The severe depression of membrane responsiveness induced by lidocaine was reversed completely. 
cycle length $800 \mathrm{msec}$. At concentrations of $1 \times 10^{-7}$ and $1 \times 10^{-8} \mathrm{~mole} /$ liter, there was essentially no change from control in the peak $V_{\max }$. At $1 \times 10^{-5} \mathrm{~mole} / \mathrm{liter}$, mean peak $V_{\max }$ increased to $551 \pm 12 \mathrm{v} / \mathrm{sec}$ which was not statistically significant $(P<0.1)$. There was no decrease in the peak $V_{\max }$ in any fiber studied until lidocaine in the Tyrode solution reached a concentration of $5 \times 10^{-6}$ mole/liter. The decrease in peak $V_{\max }$ seen at $5 \times 10^{-5}$ mole/liter in some fibers (see Fig. $10 \mathrm{~A}$ ) was not accompanied by a decrease in the transmembrane voltage of the Purkinje fiber. Although the peak $V_{\max }$ fell in some fibers at the $5 \times 10^{-5} \mathrm{M}$ concentration and the mean peak $V_{\max }$ fell to $491 \pm 17 \mathrm{v} / \mathrm{sec}(P<0.05)$, it was only at $1 \times 10^{-4}$ mole/liter that the mean peak $V_{\max }$ for the group of fibers became impressively lower than control, $404 \pm 25 \mathrm{v} / \mathrm{sec}(P<0.001)$.

To further examine the effects of lidocaine on the $V_{\max }$ of Purkinje fibers, this variable was measured as a function of transmembrane activation voltage in eight experiments. A large number of measurements of $\mathrm{V}_{\max }$ were obtained as membrane voltage was varied in small increments. The paired observations of $V_{\max }$ and MAV were then plotted (see Fig. $10 \mathrm{~A}$ ). Under control conditions, the usual S-shaped relationship between $V_{\max }$ and MAV (membrane responsiveness), first described for Purkinje fibers by Weidmann (24), was found. The experimental points always showed a good fit to the curve computed with the Weidmann formula (24). Exposure to $1 \times 10^{-7}$ and $1 \times 10^{-6} \mathrm{M}$ lidocaine did not alter this relationship. Concentrations of $1 \times 10^{-5}$ mole/liter either did not alter the relationship between $V_{\max }$ and MAV or actually increased the peak $V_{\max }$ and made the curve steeper (see Fig. $10 \mathrm{~A}$ ). Concentrations of $5 \times 10^{-5}$ mole/liter produced variable effects on the relationship; in some fibers, no effect was seen, in others, a decrease in the peak $V_{\max }$ occurred and the curve shifted slightly downward and to the right (see Fig. $10 \mathrm{~A}$ ). Lidocaine, in concentrations of $1 \times 10^{-4}$ mole/liter or greater, invariably caused significant decreases in the peak $V_{\max }$ and a pronounced downward and rightward shift of the curve (see Fig. $10 \mathrm{~A}$ and $\mathrm{B}$ ).

Perhaps it is not quite correct to state that the relationship between $V_{\max }$ and MAV was essentially unaltered by lidocaine concentrations between $1 \times 10^{-6}$ and $5 \times 10^{-5} \mathrm{~mole} / \mathrm{liter}$. It is true that the features usually used to characterize the relationship, peak $V_{\max }$ and shifts on the voltage axis (24), rarely changed at a concentration of $5 \times 10^{-5}$ mole/liter and never occurred at lower concentrations. However as previously indicated, the transmembrane voltage at which Purkinje fiber activation was first possible became progressively higher (more negative) with increases in concentration over the range of $1 \times 10^{-6}$ to $5 \times 10^{-5} \mathrm{~mole} / \mathrm{liter}$ (see Fig. 7); in effect, the tail of the S-shaped curve was lost (see Fig. 10 A). During exposure to these concentrations, the $V_{\max }$ was appropriate to the MAV over the entire transmembrane voltage range at which the fibers could be activated; at $1 \times 10^{-5} \mathrm{~mole} / \mathrm{liter}$, some fibers even showed a higher $V_{\max }$ at a given MAV than under control conditions. It is this loss of the tail of the S-shaped curve that can allow the effective refractory period to become long relative to action potential duration without shifts in peak $V_{\max }$ or the steep portion of the curve on the voltage axis.

Five preparations which showed depressed membrane responsiveness after $30 \mathrm{~min}$ exposure to toxic concentrations of lidocaine $\left(\geq 1 \times 10^{-4}\right.$ mole/liter) were subsequently perfused with normal Tyrode solution. Membrane responsiveness was restored to normal in each fiber within an hour after removing lidocaine from the Tyrode solution. (see Fig. 10 B).

\section{Effects of lidocaine on automaticity in Purkinje} fibers

The effects of lidocaine on automaticity was examined in six spontaneously beating Purkinje fibers. A concentration of $1 \times 10^{-8} \mathrm{~mole} / \mathrm{liter}$ usually exerted a discernable negative effect. A concentration of $1 \times 10^{-5} \mathrm{~mole} /$ liter invariably caused slowing of spontaneously beating fibers by slowing the rate of phase 4 depolarization (see Fig. 11, panels A and B). This concentration often caused cessation of spontaneous firing in pacemaker cells (see Fig. 11, panel C) without causing a decrease in diastolic transmembrane voltage. The time course of this antiautomatic effect was rapid, and full effect was usually established in 10-15 min after initiating lidocaine perfusion. When $1 \times 10^{-5}$ M lidocaine abolished automaticity in Purkinje fibers, neither diastolic excitability nor such electrophysiological characteristics as maximum diastolic voltage, amplitude, or overshoot were significantly affected (see Fig. 11, panel D). The effect of lidocaine on epinephrine-induced arrhythmia or automaticity was examined in four preparations. Before lidocaine, transient exposure to high concentrations of epinephrine caused rapid spontaneous firing in Purkinje fibers (see Fig. 12). After lidocaine $\left(1 \times 10^{-8}\right.$ mole/liter), higher concentrations of epinephrine were required to increase the spontaneous firing rate a smaller amount.

It is worth emphasizing that lidocaine exerted these powerful effects on automaticity and spontaneous firing of Purkinje fibers at concentrations $\left(1 \times 10^{-6}\right.$ and $1 \times 10^{-5}$ mole/liter) which had no significant effect on the maximum diastolic voltage, amplitude, overshoot, or peak $V_{\max }$ of the Purkinje fiber action potential. Other than decreased automaticity, the only consistent effect of lidocaine at these concentrations was shortening of action potential and effective refractory period duration. 


\section{DISCUSSION}

The results of these experiments caused us to reject the hypothesis that lidocaine exerts electrophysiological effects essentially like those of procaine amide or quinidine on canine Purkinje and ventricular muscle cells. Procaine amide and quinidine possess local anesthetic properties and are known to: $(a)$ enhance automaticity in high concentrations, $(b)$ prolong the duration of the action potential and the effective refractory period in both Purkinje and ventricular muscle fibers, and $(c)$ to decrease the membrane responsiveness of Purkinje fibers in low to moderate concentrations, thereby decreasing conduction velocity (21). In this study, lidocaine: (a) never induced automaticity in Purkinje fibers, even those exposed to concentrations as extreme as $5 \times 10^{-4}$ mole/liter, $(b)$ decreased both action potential duration and effective refractory period in
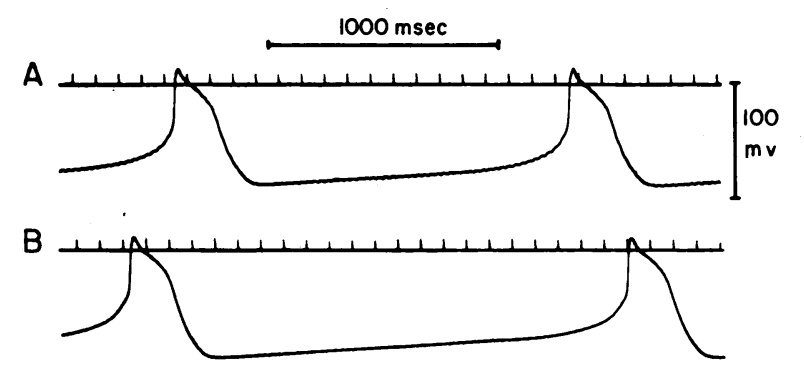

C

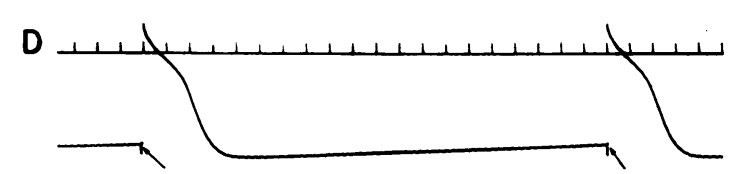

FIGURE 11 The effects of lidocaine on automaticity in a canine Purkinje fiber. Each recording was made from the same cell in a canine PF. Panel A shows the transmembrane voltage recorded from the fiber under control conditions, when it was beating spontaneously at a rate of $36 / \mathrm{min}$. Note the depolarization occurring during diastole and the smooth, concave upswing as the membrane voltage approaches the critical firing level. Both features are typical of an automatic cell. Panels B-D were recorded during perfusion of the fiber with $1 \times 10^{-5} \mathrm{M}$ lidocaine. Panel $\mathrm{B}$, recorded $5 \mathrm{~min}$ after initiating lidocaine perfusion, shows little change in the configuration of the transmembrane action potential and a slight decrease in the slope of diastolic depolarization (spontaneous rate, $28 / \mathrm{min}$ ). Panel $\mathrm{C}$ shows that after $9 \mathrm{~min}$ of exposure to this concentration of lidocaine, spontaneous beating ceased altogether and only a steady transmembrane resting potential was recorded. Panel D recorded $13 \mathrm{~min}$ after lidocaine demonstrates that even though automaticity had been abolished, the fiber was excitable by electrical pulses and had a reasonably normal transmembrane action potential. The stimulus artifact is indicated by the arrows.

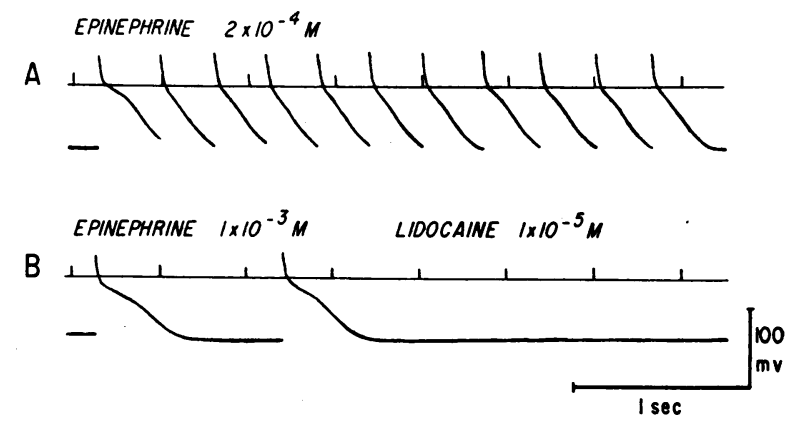

Figure 12 The response of a Purkinje fiber to L-epinephrine and the alteration of this response caused by lidocaine. In each panel, the upper trace records time marks every 500 msec and the lower trace transmembrane voltage. Time and voltage calibrations are shown. Under control conditions, the fiber was spontaneously beating at a rate of $28 / \mathrm{min}$. Epinephrine was added to the bath to give a final concentration of $2 \times 10^{-4}$ mole/liter and resulted in the rapid firing shown in panel A. After epinephrine was washed out of the bath, the fiber resumed slow spontaneous beating. $1 \times 10^{-5} \mathrm{M}$ lidocaine in Tyrode solution, was used to perfuse the preparation. After $20 \mathrm{~min}$, spontaneous beating ceased and epinephrine $\left(2 \times 10^{-4}\right.$ mole/liter) was again added, this time without effect. The bath epinephrine concentration was increased to $1 \times 10^{-3} \mathrm{~mole} / \mathrm{liter}$ and the sporadic firing shown in panel $B$ resulted. The preparation again ceased beating when the epinephrine was washed out of the bath.

Purkinje and ventricular muscle fibers, and (c) did not decrease peak $V_{\max }$ or membrane responsivenes at low or moderate concentrations. With regard to these three effects, lidocaine resembles diphenylhydantoin (19) but not procaine amide or quinidine (21). Another notable difference between lidocaine and procaine amide or quinidine was the rapidity and completeness with which reversal of electrophysiological effects was obtained when even toxic concentrations of lidocaine were removed from the perfusate.

Lidocaine did share with procaine amide and quinidine two properties: (a) suppression of automaticity in Purkinje fibers and $(b)$ a characteristic alteration in the relationship between action potential duration and effective refractory period in both Purkinje and ventricular muscle fibers. Lidocaine suppressed automaticity in Purkinje fibers, predominantly by altering phase 4 depolarization; this anti-automatic effect was present even at low concentrations (e.g. $1 \times 10^{-6} \mathrm{~mole} / \mathrm{liter}$ ) and showed a concentration-dependent increase in both rapidity of onset and extent of suppression. Although lidocaine decreased the duration of both the action potential and effective refractory period of Purkinje and ventricular muscle fibers, shortening of action potential duration was greater than shortening in the effective refractory period (see Fig. 8). Thus, the relationship between full recovery of repolarization and recovery of excitability was altered in the same direction by lidocaine 
as by procaine amide and quinidine, although absolute changes in these two variables were opposite in direction.

The differences in electrophysiological properties between lidocaine and procaine amide or quinidine are particularly interesting when one considers the structural similarities of lidocaine and procaine amide. Although the local anesthetics are often discussed as if they had uniform properties, the literature reveals that differences between individual local anesthetics have often been appreciated when two or more local anesthetics have been examined in a given biological system (2528). Quantitative differences among the local anesthetics have been explained by differences in $\mathrm{pK}_{\mathrm{a}}$. Differences in $\mathrm{pK}_{\mathrm{a}}$ determine differences in the ratio of free base (B) to cationic form $\left(\mathrm{BH}^{+}\right)$between the various compounds at physiological $\mathrm{pH}$. Whether a particular local anesthetic exists as $\mathrm{B}$ or in the form $\mathrm{BH}^{+}$determines, in large part, how well the drug crosses cell membranes and the intensity of its pharmacological effect (28, 29). For instance, the $\mathrm{B}: \mathrm{BH}^{+}$has been shown to be important in determining local anesthetic potency in producing peripheral nerve block $(29,30)$. The $\mathrm{pK}_{\mathrm{a}}$ of lidocaine is 7.85 (30), a value considerably lower than any other commonly used local anesthetic. This means, for example, that at $\mathrm{pH} 7.36$ (the $\mathrm{pH}$ of the Tyrode solution in our experiments) lidocaine has a $\mathrm{B}: \mathrm{BH}^{+}$ nearly 10 times that of procaine with its $\mathrm{pK}_{\mathrm{a}}$ of 8.95 . The low $\mathrm{pK}_{\mathrm{a}}$ of lidocaine relative to other local anesthetics also means that its $\mathrm{B}: \mathrm{BH}^{+}$is more responsive to changes of $\mathrm{pH}$ in the physiological range. However, the qualitative nature of the differences between lidocaine and procaine amide could not be explained by differences in the $\mathrm{B}: \mathrm{BH}^{+}$due to differences in $\mathrm{pK}_{\mathrm{a}}$.

After studying the effects produced by a wide range of lidocaine concentrations, we feel that the effects seen at $1 \times 10^{-5} \mathrm{~mole} / \mathrm{liter}(2.34 \mu \mathrm{g} / \mathrm{ml})$ correspond to the effects produced by therapeutic concentrations (2-5 $\mu \mathrm{g} / \mathrm{ml}$ ) in man (6). Certainly, the concentration corresponding to therapeutic levels in man must be less than $1 \times 10^{-4}$ mole/liter since this concentration had effects which would produce widening of the QRS complex of the electrocardiogram in vivo; full antiarrhythmic doses of lidocaine do not cause widening of the QRS complex in man (13). We have therefore used the effects produced by the $1 \times 10^{-8} \mathrm{M}$ concentration in proposing how lidocaine might exert its antiarrhythmic effect in vivo. It is interesting that the antiarrhythmic lidocaine plasma concentration of $2-5 \mu \mathrm{g} / \mathrm{ml}$ in man (6) is so similar to the in vitro concentration thought to produce comparable effects. We recognize the fact that many difficulties are encountered in attempts to relate in vivo plasma concentrations to the concentration of drugs perfusing isolated preparations of cardiac tissue (22). The similarity between the effective in vitro and in vivo concentrations may be due, in part, to the fact that lidocaine, unlike procaine amide or quinidine, is not significantly bound to plasma proteins (30-32) and diffuses readily into the tissues $(25,30)$.

Having identified such substantial differences between lidocaine and the standard antiarrhythmic drugs, procaine amide and quinidine, we will propose mechanisms by which lidocaine might exert its clinical antiarrhythmic effects. Hoffman has proposed that arrhythmias may be produced by: $(a)$ enhanced automaticity, $(b)$ depressed conductivity, or $(c)$ combinations of enhanced automaticity and depressed conductivity $(18,33)$. Clinical ventricular arrhythmias caused by either widespread or local areas of enhanced automaticity in the HisPurkinje system should be abolished by lidocaine treatment, since low concentrations suppress automaticity induced by a variety of causes.

Depressed conductivity can lead to arrhythmias by allowing reentry to occur in focal areas which have the appropriate geometrical arrangement and functional properties. The simple model often utilized to explain ventricular reentrant rhythms is a Purkinje fiber which divides into two branches which almost immediately terminate on a strip on ventricular muscle (18). One branch must demonstrate unidirectional block so that, if conduction velocities and refractory periods in the component tissues are appropriate, impulses can reenter the circuit one or more times, leading to single premature beats or runs of "ectopic rhythm."

On the basis of observations made in this study, lidocaine could abolish such reentrant ventricular arrhythmias by altering conductivity in at least two ways. First, beneficial alterations in conductivity in a reentrant circuit might result from the lengthening of the effective refractory period relative to action potential duration in either Purkinje or ventricular muscle fibers. The change in the relationship between these two variables occurs at "therapeutic" drug concentrations where membrane responsiveness is not diminished, but premature stimuli are unable to activate the fiber until higher transmembrane voltages are reached; this effect would cause early recirculating impulses to be completely blocked. When the fiber has repolarized to a voltage sufficient: for activation in the presence of lidocaine, $V_{\max }$ would. be unaltered or improved from predrug values at any given $\mathrm{MAV}$; conduction might therefore become incremental. i.e., increase in velocity with each unit of spacetraversed. The opportunity to utilize this antiarrhythmic mechanism might be provided by the decrease that lidocaine produces in Purkinje and ventricular muscle fiber action potential duration and the fact that the decrease is relatively greater in Purkinje fibers. Therefore, if conduction time in the reentry circuit, in response to application of lidocaine, initially remained constant, the 
Purkinje fiber would repolarize to higher transmembrane voltages before the arrival of the recirculating impulse, so that MAV and $V_{\max }$ would increase, thus leading to an increment in the mean conduction velocity in the reentrant pathway. This would lead to a decrease in wavelength in the pathway and could extinguish the arrhythmia.

A second mechanism by which lidocaine could interrupt reentry circuits would be by improving membrane responsiveness and thereby improve conduction in the Purkinje fiber branch showing slowed conduction. Even if conduction in the depressed branch of the Purkinje fiber did not become normal but only improved enough to allow the impulse to penetrate further toward ventricular muscle or to be sustained for a longer time before blocking, reentry from ventricular muscle into the depressed branch would be prevented (34). Our results make this hypothesis tenable. Lidocaine is capable of shifting the curve relating $V_{\max }$ to $M A V$ upward and leftward (see Fig. $10 \mathrm{~A}$ ). An increase in $\mathrm{V}_{\max }$ would lead to improved conduction $(24,35)$. Such an improvement in membrane responsiveness would produce particularly marked improvement in conduction in tissues having low transmembrane voltages (e.g. the depressed branch of the reentry model).

In many clinical arrhythmias, both decreased conductivity and increased automaticity may play a role (33). Indeed, enhanced automaticity itself may lead to depressed conductivity. Amplitude and $\mathrm{V}_{\max }$ of action potentials evoked in Purkinje fibers are, for practical purposes, entirely dependent on membrane voltage at the time of activation (24), no matter whether a given membrane voltage has been reached: $(a)$ during repolarization of a normal action potential, $(b)$ by generalized depolarization of the membrane, or $(c)$ by phase 4 depolarization. Augmented automaticity localized to one branch of a Purkinje fiber could cause delayed conduction and block of impulses propagating into this branch; this conduction delay can be unidirectional and cause reentry (20). Application of lidocaine could diminish automaticity and thereby speed conduction and abolish reentry. Thus, lidocaine potentially has the capacity to favorably alter ventricular arrhythmias arising from any of the three general mechanisms proposed by Hoffman (18).

We have no direct evidence on the alterations of ionic mechanisms which mediate the profound changes in action potential depolarization and repolarization produced by lidocaine. However, in concentrations equivalent to therapeutic concentrations in man, lidocaine never decreases membrane responsiveness, suggesting that the availability of the sodium carrier is not reduced by these concentrations (24). Toxic concentrations, $\geq 1 \times 10^{-4}$ mole/liter, rapidly and significantly decreased membrane responsiveness indicating partial inactivation of the sodium carrier. High concentrations of local anesthetics produce a similar effect on squid axon (36). In addition, lidocaine had marked effects on repolarization in both Purkinje and ventricular muscle fibers, even at low concentrations. Lidocaine-induced shortening of the action potential is clearly attributable to shortening of phase 2 repolarization in Purkinje fibers.

The abbreviated repolarization could be due to: $(a)$ development of or increase in an inward current carried by negatively charged ions, e.g. $\mathrm{Cl}^{-},(b)$ an increase in an outward current carried by positively charged ions, e.g. $\mathrm{K}^{+},(c)$ a decrease in an inward current carried by positive ions, e.g. $\mathrm{Na}^{+}$or $\mathrm{Ca}^{++}$, or $(d)$ a decrease in an outward current carried by negative ions, e.g., $\mathrm{Cl}^{-}$. Since the ionic currents which flow when Purkinje fiber transmembrane voltage is clamped at plateau levels $(\geq-20$ mv) are complicated and disputed (37-41), selection of the ionic species mediating lidocaine's effect on repolarization is difficult. Nevertheless, the fact that lidocaine shortens ventricular muscle and Purkinje fiber action potentials at concentrations where its only other prominent effect is to suppress automaticity suggests that the ion primarily involved may be potassium. Increased sarcolemmal permeability to $\mathrm{K}^{+}$throughout the cardiac cycle would both accelerate repolarization and suppress automaticity. Lidocaine's shortening of action potential phase 2 could also be exerted by premature initiation of the increase in potassium conductance during repolarization. Lidocaine has a high affinity for phospholipids in the lipid layer of nerve and muscle cell membranes (42). By combining with sarcolemmal lipids, lidocaine could conceivably alter the number, size, or geometry of the potassium channels and lead to the observed changes in repolarization and phase 4 depolarization. However, the time course and amount of membrane current carried by $\mathrm{K}^{+}$during Purkinje fiber repolarization remains controversial and information about these events in mammalian ventricular muscle is lacking $(38,41,43)$. The potassium conductance of Purkinje fiber membrane during the cardiac cycle can be resolved into at least two components possessing markedly different functional characteristics $(43,44)$; one is voltage dependent, activated near plateau voltage levels and probably responsible, in large part, for repolarization of Purkinje fibers, while the second is time dependent, responsible for the very small currents existing after full repolarization and may be related to phase 4 depolarization. Therefore, our proposal of one change in the ionic events to explain both accelerated repolarization and suppressed phase 4 depolarization is probably greatly oversimplified.

Lidocaine and Cardiac Membrane Potentials 75 


\section{ACKNOWLEDGMENTS}

This investigation was supported in part by U. S. Public Health Service Research Grants HE-08508 and HE-05741 from the National Heart Institute and a Grant-in-Aid from the New York Heart Association.

\section{REFERENCES}

1. Southworth, J. L., V. A. McKusick, E. C. Peirce II, and F. L. Rawson, Jr. 1950. Ventricular fibrillation precipitated by cardiac catheterization. J. Amer. Med. Ass. 143: 717.

2. Hitchcock, P., and K. K. Keown. 1959. The management of cardiac arrhythmias during cardiac surgery. S. Med. J. 52: 702.

3. Likoff, W. 1959. Cardiac arrhythmias complicating surgery. Amer. J. Cardiol. 3: 427.

4. Weiss, W. A. 1960. Intravenous use of lidocaine for ventricular arrhythmias. Anesth. Analg. 39: 369.

5. Frieden, J. 1965. Antiarrhythmic drugs. VII. Lidocaine as an antiarrhythmic agent. Amer. Heart J. 70: 713.

6. Gianelly, R., J. O. von der Groeben, A. P. Spivack, and D. C. Harrison. 1967. Effect of lidocaine on ventricular arrhythmias in patients with coronary heart disease. $N$. Engl. J. Med. 277: 1215.

7. Lown, B., A. M. Fakhro, W. B. Hood, and G. W. Thorn. 1967. The coronary care unit. New perspectives and directions. J. Amer. Med. Ass. 199: 188.

\&. Spracklen, F. H. N., J. J. Kimerling, E. M. M. Besterman, and J. W. Litchfield. 1968. Use of lignocaine in treatment of cardiac arrhythmias. Brit. Med. J. 1: 89.

9. Jewitt, D. E. Y. Kishon, and M. Thomas. 1968. Lignocaine in the management of arrhythmias after acute myocardial infarction. Lancet. 1: 266.

10. Harrison, D. C., J. H. Sprouse, and A. G. Morrow. 1963. The antiarrhythmic properties of lidocaine and procaine amide. Clinical and physiologic studies of their cardiovascular effects in man. Circulation. 28: 486.

11. Austen, W. G., and J. M. Moran. 1965. Cardiac and peripheral vascular effects of lidocaine and procaine amide. Amer. J. Cardiol. 16: 701.

12. Schumacher, R. R., A. D. Lieberson, R. H. Childress, and J. F. Williams, Jr. 1968. Hemodynamic effects of lidocaine in patients with heart disease. Circulation. 37: 965.

13. Bigger, J. T., Jr., and R. H. Heissenbuttel. 1969. The use of procaine amide and lidocaine in the treatment of cardiac arrhythmias. Progr. Cardiovasc. Dis. 11: 515.

14. Lieberman, N. A., R. S. Harris, R. I. Katz, H. M. Lipschutz, M. Dolgin, and V. J. Fisher. 1968. The effects of lidocaine on the electrical and mechanical activity of the heart. Amer. J. Cardiol. 22: 375.

15. Greenspan, K., T. J. Lord, E. F. Steinmetz, and C. Fisch. 1966. Countershock, xylocaine and quinidine in the treatment of digitalis toxicity. J. Indiana State Med. Ass. 59: 148.

16. Hilmi, K. I., and T. J. Regan. 1968. Relative effectiveness of antiarrhythmic drugs in treatment of digitalisinduced ventricular tachycardia. Amer. Heart. J. 76: 365.

17. Katz, M. J., and R. S. Zitnik. 1966. Direct current shock and lidocaine in the treatment of digitalis-induced ventricular tachycardia. Amer. J. Cardiol. 18: 552.
18. Hoffman, B. F. 1966. The genesis of cardiac arrhythmias. Progr. Cardiovasc. Dis. 8: 319.

19. Bigger, J. T., Jr., A. L. Bassett, and B. F. Hoffman. 1968. Electrophysiological effects of diphenylhydantoin on canine Purkinje fibers. Circ. Res. 22: 221.

20. Singer, D. H., R. Lazzara, and B. F. Hoffman. 1967. Interrelationships between automaticity and conduction in Purkinje fibers. Circ. Res. 21: 537.

21. Hoffman, B. F. 1958. Action of quinidine and procaine amide on single fibers of dog ventricle and specialized conducting system. An. Acad. Brasil. Cienc. 29: 365.

22. Strauss, H. C., J. T. Bigger, Jr., A. L. Bassett, and B. F. Hoffman. 1968. Actions of diphenylhydantoin on the electrical properties of isolated rabbit and canine atria. Circ. Res. 23: 463.

23. Kao, C. Y., and B. F. Hoffman. 1958. Graded and decremental response in heart muscle fibers. Amer. $J$. Physiol. 194: 187.

24. Weidmann, S. 1955. The effect of the cardiac membrane potential on the rapid availability of the sodium-carrying system. J. Physiol. (London). 127: 213.

25. Bianchi, C. P., and T. C. Bolton. 1967. Action of local anesthetics on coupling systems in muscle. J. Pharmacol. Exp. Ther. 157: 388 .

26. Weidmann, S. 1955. Effects of calcium ions and local anaesthetics on electrical properties of Purkinje fibres. J. Physiol. (London). 129: 568.

27. Narahashi, T., and J. W. Moore. 1968. Neuroactive agents and nerve membrane conductances. J. Gen. Physiol. 51: 93s.

28. Ritchie, J. M., and B. R. Ritchie. 1968. Local anesthetics: effect of $\mathrm{pH}$ on activity. Science (Washington). 162: 1394.

29. Ritchie, J. M., and P. Greengard. 1966. On the mode of action of the local anesthetics. Annu. Rev. Pharmacol. 6: 405 .

30. Truant, A. P., and B. Takman. 1959. Differential physical-chemical and neuropharmacologic properties of local anesthetic agents. Anesth. Analg. 38: 478.

31. Keenaghan, J. B. 1968. The determination of lidocaine and prilocaine in whole blood by gas chromatography. Anesthesiology. 29: 110.

32. Sung, C.-Y., and A. P. Truant. 1954. The physiological disposition of lidocaine and its comparison in some respects with procaine. J. Pharmacol. Exp. Ther. 112: 432.

33. Hoffman, B. F., and P. F. Cranefield. 1964. The physiological basis of cardiac arrhythmias. Amer. J. Med. 37: 670

34. Schmitt, F. O., and J. Erlanger. 1928. Directional differences in the conduction of the impulse through heart muscle and their possible relation to extrasystolic and fibrillary contractions. Amer. J. Physiol. 87: 326.

35. Weidmann, S. 1956. Elektrophysiologie der Herzmuskelfaser. Huber, Bern.

36. Taylor, R. E. 1959. Effect of procaine on electrical properties of squid axon membrane. Amer. J. Physiol. 196: 1071 .

37. Dudel, J., K. Peper, R. Rüdel, and W. Trautwein. 1967. The dynamic chloride component of membrane current in Purkinje fibers. Pfluegers Arch. Gesamte Physiol. Menschen Tiere. 295: 197.

38. Dudel, J., K. Peper, R. Rüdel, and W. Trautwein. 1967. The potassium component of membrane current in 
Purkinje fibers. Pfluegers Arch. Gesamte Physiol. Menschen Tiere. 296: 308.

39. Dudel, J., K. Peper, and W. Trautwein. 1966. The contribution of $\mathrm{Ca}^{++}$ions to the current voltage relation in cardiac muscle (Purkinje fibers). Pfuegers Arch. Gesamte Physiol. Menschen Tiere. 288: 262.

40. Reuter, H. 1967. The dependence of slow inward current in Purkinje fibres on the extracellular calciumconcentration. J. Physiol. (London). 192: 479.

41. Peper, K., and W. Trautwein. 1968. A membrane current related to the plateau of the action potential of Purkinje fibers. Pfluegers Arch. Gesamte Physiol. Menschen Tiere. 303: 108 .

42. Feinstein, M. B. 1964. Reaction of local anesthetics with phospholipids. A possible chemical basis for anesthesia. J. Gen. Physiol. 48: 357.

43. Noble, D., and R. W. Tsien. 1968. The kinetics and rectifier properties of the slow potassium current in cardiac Purkinje fibres. J. Physiol. (London). 195: 185

44. McAllister, R. E., and D. Noble. 1966. The time and voltage dependence of the slow outward current in cardiac Purkinje fibres. J. Physiol. (London). 186: 632. 